\title{
Successful treatment of a 20 -year nonhealing venous leg ulcer in a patient with systemic lupus erythematosus
}

Cenk Eray Yildiz ${ }^{1}$, Cenk Conkbayir², Halil Erkam Tolgay ${ }^{1}$, Kadir Ceviker ${ }^{3}$, Mustafa Canikoglu4 Omer Ali Sayin ${ }^{5}$, Murat Ugurlucan ${ }^{5}$

\author{
${ }^{1}$ Department of Cardiovascular Surgery, Institute of Cardiology, Istanbul University, \\ Istanbul, Turkey \\ ${ }^{2}$ Department of Cardiology, Faculty of Medicine, Near East University, Nicosia, Cyprus \\ ${ }^{3}$ Department of Cardiovascular Surgery, Faculty of Medicine, Suleyman Demirel \\ University, Isparta, Turkey \\ ${ }^{4}$ Department of Cardiovascular Surgery, Private Clinic, Izmit, Kocaeli, Turkey \\ ${ }^{5}$ Department of Cardiovascular Surgery, Medical Faculty, Istanbul University, Istanbul, \\ Turkey
}

Submitted: 9 May 2016

Accepted: 20 July 2016

Arch Med Sci 2017; 13, 3: 691-695

DOI: https://doi.org/10.5114/aoms.2017.67289

Copyright $\odot 2017$ Termedia \& Banach

Chronic relapsing ulcerative wounds affecting the lower extremities are frequently associated with venous insufficiency leading to edema. It is a vicious circle unless leg edema is resolved with additional care; otherwise the size and depth of the ulcer as well as symptoms of the patients increase devastatingly [1-3].

Systemic lupus erythematosus is a chronic autoimmune multisystemic, inflammatory disorder without an identified etiology, affecting skin, kidneys, lungs, liver, the nervous system, heart and circulation [4, 5]. Vascular disorders involving the arteries and veins during the course of the disease are common and may lead to significant morbidity and even mortality [6].

Here, we present successful treatment of a leg ulcer, which had existed for over 20 years, in 3 months with a 3-step treatment protocol including treatment of venous reflux, negative pressure wound treatment followed by thrombin-enriched thrombocyte concentrate in a 45 -year-old patient with systemic lupus erythematosus.

A 45-year-old male patient was admitted to our institution with a $10 \times 12 \mathrm{~cm}$ in diameter pretibial leg ulcer. His body surface area was $2.5 \mathrm{~m}^{2}$ and his body mass index was $38 \mathrm{~kg} / \mathrm{m}^{2}$. The history revealed being followed irregularly with the diagnosis of systemic lupus erythematosus and use of prednisolone $4 \mathrm{mg}$ daily. The ulcer started 20 years ago after a traffic accident and never healed. He had depressive symptoms such feeling hopeless, irregular and inadequate feeling, and loss of joy of life.

The ulcer was dirty, infected and smelled bad (Figure 1 A). Laboratory work-up indicated increased an erythrocyte sedimentation rate of $103 \mathrm{~mm}$ at $1 \mathrm{~h}$ (normal: $1-10$ ), C-reactive protein (CRP) of $53 \mathrm{mg} / \mathrm{l}$ (normal: 1-10), white blood cell count of $12,000 \mathrm{~g} / \mathrm{l}$ and $\alpha 1, \beta 1$ and $\beta 2$ and $\gamma$ levels in protein electrophoresis. Cultures were taken immediately and microscopic evaluation showed Pseudomonas aeruginosa colonization. Ciprofloxacin $750 \mathrm{mg}$ twice daily was initiated according to the antibiogram results.

The nonhealing ulcer was investigated multifactorially. The prednisolone that he had been on for many years was discontinued. An exercise program was started and a protein-rich, low-carbohydrate diet was ad-

\author{
Corresponding author: \\ Assoc. Prof. Cenk Eray Yildiz \\ Department of \\ Cardiovascular Surgery \\ Institute of Cardiology \\ Istanbul University \\ Haseki Cad. No: 29/31, \\ 34304 Fatih \\ Istanbul, Turkey \\ Phone: +90 212459 2000, \\ +90 5323838804 \\ Fax: +90 2124592069 \\ E-mail: ceyildiz@hotmail.com
}



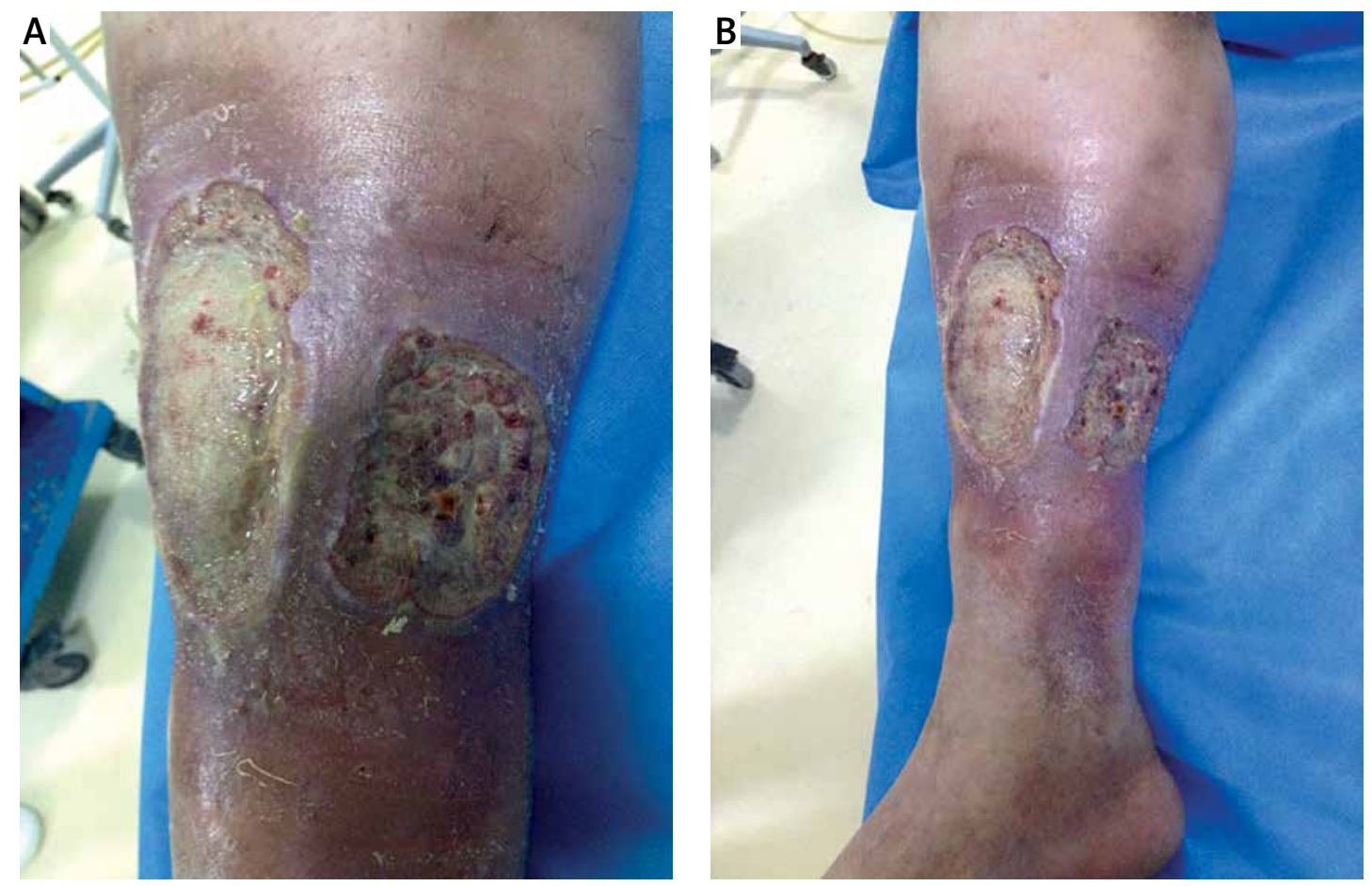

Figure 1. A - Leg and ulcer before RF ablation, B - leg and ulcer after RF ablation

A

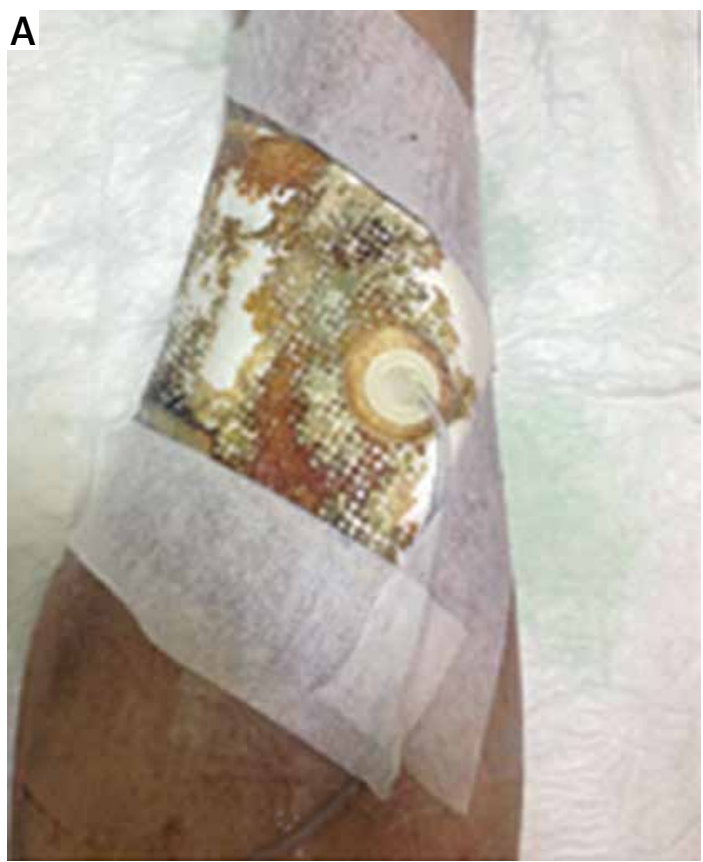

Figure 2 A, B. Pico IFU negative pressure aspiration therapy

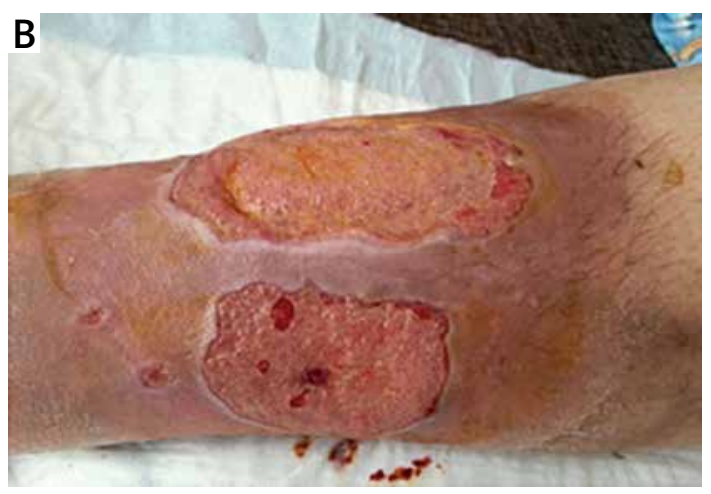

vised. Lower extremity Doppler ultrasonography revealed grade 4 reflux in the superficial veins of sizes reaching up to $6-10 \mathrm{~mm}$. Further hematologic tests for coagulopathies including protein $C$ and $\mathrm{S}$ deficiency, factor 5 Leiden mutation, and homocysteinemia were negative. Rheumatologic tests indicated homogeneous strong positive anti-nuclear antibodies and an anti-ds-DNA value of 204 IU/ $\mathrm{ml}$, confirming the diagnosis of systemic lupus erythematosus. Hydroxychloroquine 200 mg/day was prescribed.

We decided to proceed with a three-step treatment protocol starting with endovenous radiofrequency ablation (Venefit, VNUS Closure, Covidien, NY, USA) of bilateral great and lesser saphenous veins (Figure $1 \mathrm{~B}$ ). His legs were covered with elastic bandages after the procedure and he was discharged home the next day with compression 

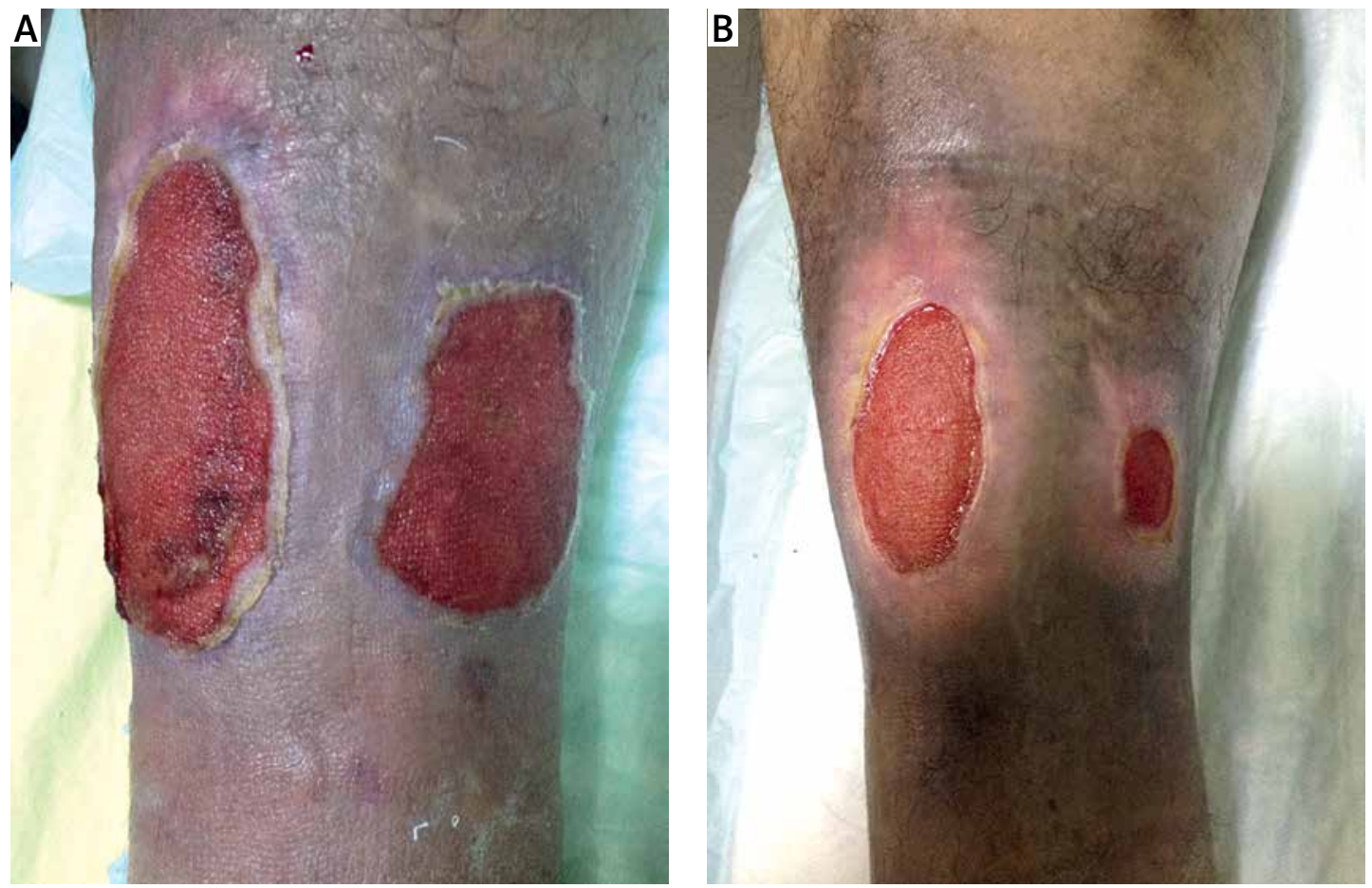

Figure 3 A, B. Status of the ulcer after cell injection - note the tissue hypertrophy

stockings for at least 2 months and medications of aspirin $100 \mathrm{mg}$ daily and micronized purified flavonoid fraction (Daflon 500) two times per day. In the meantime wound care was provided with Pico IFU (Global Excl. USA Sterile Product), a miniaturized single use $80 \mathrm{~mm} \mathrm{Hg}$ negative pressure wound treatment system (Figures 2 A, B). As the last step, an autologous thrombocyte concentrate was prepared with a combination of $6 \mathrm{ml}$ of ACD-A solution (citric acid, sodium citrate, dextrose combination) with $54 \mathrm{ml}$ of autologous blood. The red blood cells were removed from the solution, enriched with undifferentiated multipotent CD34+ cells, and $10 \mathrm{ml}$ of solution was obtained in the end. $4 \mathrm{ml}$ of solution was injected around the ulcer, and the remaining $6 \mathrm{ml}$ was saved for wound closure after combining with thrombin. Autologous thrombin was combined with $6 \mathrm{ml}$ of blood in a tube containing $1 \mathrm{ml}$ of ACD-A and $1.7 \mathrm{ml}$ of calcium to make $10 \mathrm{ml}$ of solution and incubated at room temperature for $45 \mathrm{~min}$. At the end, the mixture of thrombin and platelets at a range of $1 / 3$ revealed a rather solid gel-membrane in $5 \mathrm{~min}$, indicating that the platelets were sufficiently active $[7,8]$. This gel was used as a wound dressing in our patient, and the wound was closed for 7 days. On the third day, the wound was checked for infection and it was left for a natural course after the $8^{\text {th }}$ day (Figures 3 A, B). Regular wound care was performed then after and at the end of the $6^{\text {th }}$ month the size of the wound decreased by $70 \%$ without signs of infection (Figure 4).

Many factors contribute to the pathogenesis of leg ulcers. Most patients have venous stasis due to chronic venous insufficiency. Chronic venous hypertension either due to primary or secondary venous disease and incompetence resulting in reflux is the underlying pathology in most cases; however, inflammatory reactions, leucocyte infiltration, platelet adhesion, pericapillary fibrin

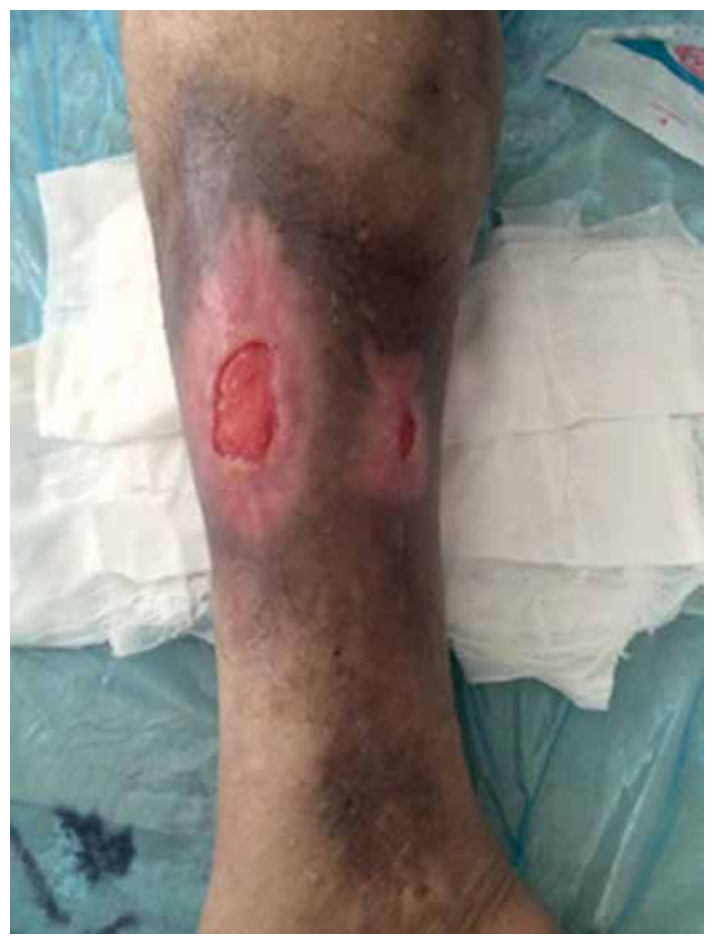

Figure 4. Normal twice daily wound care with isotonic solution - note the status of the wound after 2 months 
accumulation, and macrophages filling the tissues result in hypoxia, cell death and eventually ulceration. The diagnosis of leg ulcer can be made based on medical history, inspection, palpation of the skin, comparison of the temperature of the ulcerated leg, palpation of arteries, fascia holes, presence and degree of edema, firm-painful lymphatic channels, and functional testing to assess peripheral occlusive arterial disease or identify superficial and deep venous reflux of the legs. Other causes of chronic leg ulcers may be hematologic diseases, autoimmune diseases, genetic defects, infectious diseases, primary skin diseases, cutaneous malignant states, use of intradermal medications and therapeutic procedures, and numerous exogenous factors [1, 2]. At this point, a clear history and differential diagnosis are crucial.

Vascular pathologies are common in the course of systemic lupus erythematosus $[5,6]$. They either occur as direct complications of the disease or develop as comorbidities due to the hematologic disturbances and side effects of the immunosuppressive medications used for the treatment of systemic lupus erythematosus. Vasculopathy in the presence of an inflammatory environment is very common [6]. It is also associated with increased thrombotic events occurring at younger ages. Especially in systemic lupus erythematosus, unlike other autoimmune disorders or vasculitis syndromes, vascular pathologies may occur in combination of atherosclerotic and thrombotic disease as well as autoimmune vessel wall degeneration mediated with antiendothelial cell antibodies.

Venous ulcers are long lasting, frequently complicated with infections, and costly to treat. Healing requires patience and patient compliance, with a high risk of recurrence after healing disorders leading to severe debilitating symptoms in patients and causing increased loss of young, working age people from the economy. Although venous hypertension plays the major role in the etiology, treatment is more complicated than only relief of the venous stasis with interventional therapies and external compression. Ulcers usually require combination treatment and proper care, otherwise they may get infected, leading to gangrene and in extreme cases eventually amputation $[9,10]$. When necessary, a home wound care team may be installed.

Venous ulcers are chronic disorders. They not only lead to a physical and economical burden to the healthcare systems but also cause a serious psychological reaction due to restrictions, ill feeling, and increasing and/or relapsing symptoms despite therapeutic attempts. The patients may end up experiencing anxiety or depression requiring therapy. The causes of emotional changes are also due to additional soft (skin and muscle) and hard tissue (joint and bone) changes. The consequences of depressive symptoms such as weight gain, immobilization, and inadequate alimentation may also negatively affect the venous insufficiency and the ulcer [11].

Our patient had depressive symptoms, and he was persuaded about a possible treatment of his nonhealing stasis ulcer with multimodality approaches. Following the treatment of venous reflux, the wound of our patient was stabilized with Pico IFU negative pressure application, which was followed by autologous platelet concentration injection as well as a platelet-rich gel-membrane dressing applied at the end of the process to facilitate healing [12].

In conclusion, venous ulcer is an important health problem, and treatment is quite burdensome and usually lasts long. Despite advances in medicine, cure is not very likely and ulcers may relapse if precautions are not taken. Treatment has to be multifactorial, combining the treatment of insufficiency of the venous system and wound care.

Nonhealing leg ulcers have a complex etiology and lead to important socioeconomic problems throughout the world. Usually the patients are unfortunately neglected. Together with our 3-step treatment protocol applied in one of our patients, we wanted to stress the successful therapy of long-lasting venous ulcers with patients and careful care.

\section{Conflict of interest}

The authors declare no conflict of interest.

\section{References}

1. Varicose Veins in the Legs: The Diagnosis and Management of Varicose Veins. National Clinical Guideline Centre (UK). London: National Institute for Health and Care Excellence (UK) 2013.

2. Green J, Jester R, McKinley R, Pooler A. The impact of chronic venous leg ulcers: a systematic review. J Wound Care 2014; 23: 601-12.

3. Dowsett C, Grothier L, Henderson V, et al. Venous leg ulcer management: single use negative pressure wound therapy. Br J Community Nurs 2013; Suppl: S6, S8-10, S12-5.

4. Banys A, Kazmierski J, Jaszewski R. Psychiatric manifestations in a patient after surgical management of aortic stenosis of systemic lupus erythematosus Arch Med Sci 2011; 7: 342-4.

5. Kang SC, Hwang SJ, Chang YS, Chou CT, Tsai CY. Characteristics of comorbidities and costs among patients who died from systemic lupus erythematosus in Taiwan. Arch Med Sci 2012; 8: 690-6.

6. Pyrpasopoulou A, Chatzimichailidou S, Aslanidis S. Vascular disease in systemic lupus erythematosus. Autoimmune Dis 2012; 2012: 876456.

7. Martinez-Zapata MJ, Martí-Carvajal AJ, Solà I, et al. Autologous platelet-rich plasma for treating chronic wounds. Cochrane Database Syst Rev 2012; 10: CD006899. 
8. Carter MJ, Fylling CP, Parnell LK. Use of platelet rich plasma gel on wound healing: a systematic review and meta-analysis. Eplasty 2011; 11: e38.

9. Snyder RJ. Treatment of nonhealing ulcers with allografts. Clin Dermatol 2005; 23: 388-95.

10. Brem H, Kirsner RS, Falanga V. Protocol for the successful non-surgical treatment of venous ulcers. Am I Surg 2004; 188 (1A Suppl.): 1-8.

11. Jawien A, Szewczyk MT, Kedziora-Kornatowska K, et al. Functional and biopsychosocial restrictions among patients with a venous ulcer. Arch Med Sci 2006; 2: 36-41.

12. Hudson DA, Adams KG, Huyssteen AV, Martin R, Huddleston EM. Simplified negative pressure wound therapy: clinical evaluation of an ultraportable, no-canister system. Int Wound J 2013; 12: 195-201. 